\title{
La derogación de la cuarta de mejoras y otros correctivos a la legítima para restablecer la libertad de testar en Chile*
}

\section{María Sara Rodríguez Pinto**}

RESUMEN: El objetivo de este artículo es examinar las restricciones directas e indirectas a la libertad de testar que tiene la legislación chilena, para defender la derogación de la cuarta de mejoras y la reducción de la legítima de ascendientes y cónyuge (o conviviente civil) sobreviviente como correctivos. El método ha consistido en revisar publicaciones disponibles en Chile y cambios experimentados por la legislación, como también indicadores del impuesto a las herencias y del uso del testamento como instrumento de ordenación sucesoria. Una forma rápida y directa de aumentar la libertad de testar es la derogación de la cuarta de mejoras.

Palabras clave: Chile, sucesión forzosa, cuarta de mejoras, legítimas, libertad de testar, impuesto a las herencias y donaciones.

\section{The Repeal of the "Cuarta de Mejoras" (Forth for Improvements) and Other Amendments to the Reestablishment of the Freedom of Will in Chile}

AвSTRACт. The target of this article is to examine the direct and indirect restrictions on the freedom of will in the Chilean law, to argue for its amendment by the repealing

* Fecha de recepción: 21 de junio de 2019. Fecha de aceptación: 30 de marzo de 2020.

Para citar el artículo: RodRíGuez PinTo, M. S., "La derogación de la cuarta de mejoras y otros correctivos a la legítima para restablecer la libertad de testar en Chile", Revista de Derecho Privado, n. ${ }^{\circ}$ 39, julio-diciembre 2020, 359-382, DoI: https://doi.org/10.18601/01234366.n39.14.

** Universidad de los Andes, Santiago de Chile, Chile; profesora titular de derecho civil. Doctora en derecho, Universidad Autónoma de Madrid, Madrid, España. Contacto: msrodriguez@uandes.cl. Orcid: 0000-0002-7319-3291. 
the cuarta de mejoras (fourth for improvements) and the reduction of the succession rights of ascendants and surviving spouse (or domestic partner). The method consisted of reviewing publications available in Chile and the changes that Chilean legislation has undergone, as well as indicators of inheritance tax collection and the use of the testament as an instrument of succession planning. A fast and direct way to increase the freedom of will is the repeal of the fourth for improvements.

Keywords: Chile, law of decedent's estate, forced heirship, testamentary legal restrictions, freedom of will, inheritance tax law.

Sumario: Introducción. I. Diagnóstico del sistema mixto de legítimas y mejoras. II. La cuarta de mejoras y su urgente derogación. III. Correctivos a la legítima. Conclusiones. Referencias.

\section{Introducción}

El objetivo de este trabajo es analizar el problema de la limitación a la libertad de disponer de los bienes por testamento, por causa de un sistema sobredimensionado de asignaciones forzosas. En el caso chileno, es lo que se ha denominado un sistema mixto de legítimas y mejoras, con asignatarios forzosos cuyo número ha ido aumentando a través del tiempo.

La metodología se ha basado en la revisión de las publicaciones pertinentes disponibles en el ámbito nacional, los cambios experimentados por la legislación y los que se propone que tenga. Para evaluar la situación presente también se toman en cuenta indicadores del uso que hoy en día tiene el testamento como instrumento de ordenación sucesoria y de la escasa recaudación del impuesto a las herencias y donaciones.

Se defiende la idea de que una forma rápida y directa de aumentar la libertad de testar es la derogación de la cuarta de mejoras, como ha hecho Colombia. También se justifican reformas a la cuantía o calidad de la legítima de ascendientes y cónyuge (o conviviente civil) sobreviviente. Estas últimas reformas legales se justificarían después de derogada la cuarta de mejoras. La cuarta de mejoras es la primera de muchas restricciones que hoy se tienen en Chile para disponer libremente de los bienes para después de la muerte. No tendría sentido retocar otras asignaciones forzosas si está vigente la que menos se justifica de todas ellas.

Conforme a lo expuesto, este artículo recapitula el diagnóstico de sobredimensionamiento del sistema chileno mixto de legítimas y mejoras ( $\mathrm{I}$ ). A continuación se exponen las razones por las que una forma eficaz de corregir lo anterior es la derogación de la institución de la mejora (\$II). La tercera parte de este artículo (§III) es una evaluación del escenario que se produciría después de derogada la cuarta de mejoras en la línea de impulsar medidas correctivas adicionales en la legítima de los ascendientes y del cónyuge (o conviviente civil) sobreviviente, para adaptar las 
asignaciones forzosas a la expectativa de vida y formas de organización de la vida en los tiempos actuales.

\section{Diagnóstico del sistema mixto de legítimas y mejoras}

El sistema mixto de legítimas y mejoras ${ }^{1}$ en Chile se encuentra sobredimensionado. Esta premisa se sustenta al recapitular las reformas de las leyes n. ${ }^{\circ} 18.802$, de 1989 , n. ${ }^{\circ} 19.585$, de 1998, n. $^{\circ} 19.947$, de 2004 , y n. ${ }^{\circ} 20.830$, de 2015 . A este conjunto de normas hay que agregar el gravamen tributario que pesan sobre las liberalidades entre vivos y por causa de muerte ${ }^{2}$. Todos estos factores son los que probablemente explican la "interdicción" 3 testamentaria que existe actualmente y que, de hecho, se use con poca frecuencia del testamento como instrumento de ordenación sucesoria. La escasa recaudación del impuesto a las herencias y donaciones corroboraría la hipótesis de que son más los bienes que se transmitirían entre vivos por actos más o menos simulados, que aquellos por sucesión testada o intestada.

\section{A. Mejora para ascendientes y legítima privilegiada para el cónyuge}

Antes de la ley n. ${ }^{\circ} 18.802$, de $1989^{[4]}$, las restricciones a la libertad de testar afectaban en mayor medida a quienes tenían descendencia. La cuarta de mejoras podía favorecer solo a los hijos y descendientes, fueran o no legitimarios. Más allá del orden de la descendencia, no se formaba cuarta de mejoras. Esto significaba que se podía disponer libremente por testamento de la mitad de la herencia, mientras que la otra se reservaba para los legitimarios.

No habiendo hijos ni descendencia con derecho de representarlos, eran llamados como legitimarios los ascendientes y el cónyuge sobreviviente. Ni unos ni el otro

1 La expresión "sistema mixto" es utilizada por Claro Solar, pero el calificativo está enfatizado en cursivas. Claro Solar, L., Explicaciones de Derecho Civil chileno y comparado, Santiago, Editorial Jurídica de Chile, 2013, vol. xv, n. ${ }^{\circ}$ 1347. Debe distinguirse entre sucesión necesaria y sucesión forzosa. En Chile la sucesión por causa de muerte es siempre voluntaria, pues todos pueden aceptar o repudiar la herencia que les es deferida, testada o intestada (artículo 956 c. c. ch.). Sucesión forzosa es la que viene impuesta por ley al testador; y que se cumple "aun con perjuicio de disposiciones testamentarias expresas" (artículo 1.167 c. c. ch.). La sucesión forzosa es voluntaria, no necesaria, pues el heredero siempre puede repudiar la herencia.

2 Ley n. ${ }^{\circ} 16.271$, de impuestos a las herencias, asignaciones y donaciones, promulgada el 19 de junio de 1965 y publicada en el Diario Oficial el 10 de julio de 1965. Texto íntegro disponible en [www. leychile.cl/Navegar?idNorma=28367\&tipoVersion=0] [consultado el 30 de enero de 2020].

3 El término "interdicción” (prohibición) de la libertad de testar fue acuñado por Rodríguez Grez. Véase Rodríguez Grez, P., Instituciones de Derecho Sucesorio, Santiago, Editorial Jurídica de Chile, $2002,302$.

4 Ley n. ${ }^{\circ} 18.802$, que modifica el Código Civil, el Código de Comercio y la ley n. ${ }^{\circ}$ 16.618, promulgada el 23 de mayo de 1989 y publicada en el Diario Oficial el 9 de junio de 1989 (versión única). Texto íntegro disponible en [www.leychile.cl/Navegar?idNorma=30179] [consultado el 30 de enero de 2020]. 
eran asignatarios forzosos de mejora. Además, no habiendo descendencia, la porción del cónyuge era baja general de la herencia ${ }^{5}$. Este era llamado con los ascendientes para distribuirse la mitad legitimaria según las reglas del segundo orden de sucesión intestada ${ }^{6}$. La ley de que hablamos, sin embargo, agregó al cónyuge sobreviviente a la lista de asignatarios forzosos de cuarta de mejoras, formada hasta entonces solamente por descendientes del causante, legitimarios o no. Esta medida, que parecía responder a un amplio consenso, aumentó la porción de bienes que debía destinarse a asignaciones forzosas a tres cuartas partes del acervo transmisible, aunque no hubiera hijos, siempre que al causante sobrevivía el cónyuge.

La ley n. ${ }^{\circ} 19.585$, de $1998^{[7]}$, culmina las reformas anteriores, instituyendo a los ascendientes como asignatarios forzosos de cuarta de mejoras. Las tres cuartas partes del acervo que deben destinarse a las asignaciones forzosas se forman aunque no haya descendientes ni cónyuge sobreviviente, bastando que sobreviva al causante uno o más ascendientes, de cualquier edad y situación patrimonial. En todos estos casos el causante no ha podido disponer libremente sino de una cuarta parte de sus bienes.

Este resultado fue recibido negativamente por varios autores. Para unos, esta ley contrariaba lo que debía ser un nuevo derecho sucesorio que, tomando en cuenta el aumento en la expectativa de vida, redujera la limitación a la facultad de testar que suponían las asignaciones forzosas ${ }^{8}$. La nueva ley constituía una verdadera interdicción testamentaria, "un dirigismo sucesorial inaceptable" . No solo la sociología familiar había cambiado, se pensaba, pues tampoco subsistía el propósito de mantener la unidad del patrimonio, porque esto se conseguía por otros mecanismos ${ }^{10}$. En recapitulaciones posteriores se han propuesto fuertes reducciones en la legítima ${ }^{11}$. Esta solo debería favorecer a hijos menores de edad o discapacitados ${ }^{12}$; en tanto que a los ascendientes

5 Artículo 959, 5..$^{\circ}$ c. c. ch., derogado por la ley n. ${ }^{\circ} 19.585$, de 1998.

6 Artículo 989 c.c.ch.

7 Ley n. 19.585 , que modifica el Código Civil y otros cuerpos legales en materia de filiación, promulgada el 13 de octubre de 1998 y publicada en el Diario Oficial el 26 de octubre de 1998 (versión única). Texto íntegro disponible en [www.leychile.cl/Navegar?idNorma=126366] [consultado el 30 de enero de 2020].

8 Domínguez Benavente, R. y Domínguez Águila, R., Apéndice a la Segunda edición actualizada de Derecho Sucesorio. Modificación al contenido de la obra, Santiago, Editorial Jurídica de Chile, 1998, 21. En esta línea, Barría Paredes, M., Asignaciones forzosas y libertad de testar, Santiago, Legal Publishing Chile, 2015, 243-245.

9 Rodríguez Grez, Instituciones de Derecho Sucesorio, op . cit., 302 (énfasis del autor). En el mismo sentido, Martinic Galetovic, M. D., "Las asignaciones forzosas y la libertad de testar en el Derecho chileno", Revista Jurídica , n. ${ }^{\circ}$ 5, 2002, 69-75, disponible en [http://dspace.uces.edu.ar:8180/xmlui/ bitstream/handle/123456789/407/Las_asignaciones_forzosas.pdf?sequence=1] [consultado el $30 \mathrm{de}$ enero de 2020].

10 SaAvedra Alvarado, E., “Autonomía de la voluntad y protección de la familia frente a la actual realidad sucesoria: la búsqueda de nuevos equilibrios entre dos principios fundamentales", en CorRAL Talciani, H. (coord.), Estudios de Derecho Civil, II, Santiago, Editorial LexisNexis, 2007, 113-132.

11 Barría Paredes, M., Asignaciones forzosas y libertad de testar, op. cit., 5-182.

12 Ibid., 245-252. 
solo se les debería reconocer la calidad de alimentarios ${ }^{13}$. Se debería cambiar además la calidad de la legítima del cónyuge, para que pase de "legítima de sobreprotección" (como es la situación actual) a legítima de protección o asistencial ${ }^{14}$.

Hemos transitado de una crítica a la institución de los ascendientes como asignatarios de mejora al diagnóstico de la legítima del cónyuge sobreviviente sobredimensionada por la misma ley de 1998. A continuación, el desarrollo subsiguiente de su situación hereditaria.

\section{B. Legítima privilegiada del cónyuge al conviviente civil sobreviviente}

Los cambios al derecho sucesorio que produce la ley n. ${ }^{\circ} 19.585$ no experimentan modificaciones formales con la introducción de la ley n. ${ }^{\circ} 19.947$, de $2004^{[15]}$. La influencia de esta ley podría considerarse material. Con la posibilidad de divorcio vincular y segundas o terceras nupcias del causante, ocurre que puede ser llamado a concurrir con los hijos, con legítima privilegiada, un cónyuge a quien ellos después no tengan derecho a suceder. Antes de la entrada en vigencia de la ley esto era probable, por las segundas o terceras nupcias de un causante viudo o viuda de la madre o padre de sus hijos. Con el divorcio, la frecuencia práctica de este escenario podía aumentar.

Pues bien, la ley n. ${ }^{\circ} 20.830$, de $2015^{[16]}$, asimiló la situación de sobrevivencia del conviviente civil a la del cónyuge ${ }^{17}$. Hoy puede ocurrir que el primero concurra con descendientes que no son hijos suyos, sino solo del causante, por una legítima privilegiada y "sumamente protegida". Cuando concurre con hijos que no son suyos, y que no tienen la expectativa de sucederlo en el futuro, puede afirmarse que la esta ley saca por completo la legítima de la órbita de la descendencia del causante. Por tanto, la parte de bienes que se transmite por legítima al conviviente civil puede luego transmitirse a terceros que ningún vínculo tienen con el causante.

13 Ibid., 253-254.

14 Ibid., 255-266; 267-280. El cónyuge sobreviviente no debería llevar legítima si le corresponden gananciales en la liquidación de la sociedad conyugal que tuvo con el causante, o si tiene previsión social para vivir en consideración a su edad y circunstancias. A la vez, se propone reconocer el derecho de adjudicación preferente de la vivienda que sirvió de residencia principal de la familia (artículo 1337, regla $10{ }^{\text {a }}$ c. c. ch.) solo con cargo a la mitad de gananciales de la sociedad conyugal que tuvo con el causante; pero no a su legítima en la herencia.

15 Ley n. ${ }^{\circ}$ 19.947, que establece Nueva Ley de Matrimonio Civil, promulgada el 7 de mayo de 2004 y publicada en el Diario Oficial el 17 de mayo de 2004, modificada por última vez el 21 de abril de 2015 por la ley n. ${ }^{\circ} 20.830$. Texto íntegro disponible en [www.leychile.cl/Navegar?idNorma=225128] [consultado el 30 de enero de 2020].

16 Ley $n .^{\circ} 20.830$, que crea el Acuerdo de Unión Civil, promulgada el 13 de abril de 2015 y publicada en el Diario Oficial el 21 de abril de 2015 (versión única). Texto íntegro disponible en [www.leychile.cl/Navegar?idNorma=1075210] [consultado el 30 de enero de 2020].

17 Artículo 16: "Cada conviviente civil será heredero intestado y legitimario del otro y concurrirá en su sucesión de la misma forma y gozará de los mismos derechos que corresponden al cónyuge sobreviviente. El conviviente civil podrá también ser asignatario de la cuarta de mejoras". 


\section{Gravamen tributario de la transmisión de bienes por herencia o donación}

A las actuales limitaciones a la libertad de testar se suma el gravamen patrimonial que supone el impuesto a las herencias y donaciones (ley n. ${ }^{\circ} 16.271$, de 1965). Esta ley grava las asignaciones hereditarias de forma progresiva, según la mayor o menor proximidad de parentesco del asignatario con el causante, y según la cuantía de la asignación. Los asignatarios más próximos por parentesco al causante pagan un impuesto menor que aquellos más lejanos o no emparentados en forma alguna. De la misma forma grava las donaciones entre vivos, las que se encuentran sometidas a una multitud de leyes especiales que contemplan exenciones y beneficios tributarios para ciertas liberalidades ${ }^{18}$. Las principales críticas que se hacen a este impuesto son dos: que vuelve a gravar bienes que ya tributaron en vida del causante, y que tiene tramos exentos relativamente bajos en comparación con la tendencia de otros países que mantienen vigente un impuesto de este tipo.

Hay quienes defienden la existencia de este impuesto, afirmando que se trata de gravar un incremento patrimonial en el obligado que no es renta ni valor agregado, pero que debería equipararse a renta como medida correctiva de justicia material ${ }^{19}$. Este razonamiento se compara al de quienes rechazan la perennidad del dominio y la garantía constitucional del derecho de $\operatorname{propiedad~}^{20}$. El impuesto a las herencias y donaciones recae sobre el patrimonio y no admite deducción por aquellos pagados en su formación, lo que hace que se constituya en una forma de doble tributación del mismo hecho gravado.

La única moderación de este impuesto es la exención. La legislación chilena reconoce una de carácter general, que se sitúa en 600 UTM (unidad tributaria mensual) por asignación. Hay numerosas leyes especiales que autorizan la exención total del

18 El sinsentido del impuesto a las donaciones se comprueba cuando se observa el número de leyes generales y especiales que establecen exenciones o beneficios tributarios para dichos actos jurídicos. Todo esto se simplificaría si se suprimiera el impuesto a las herencias y donaciones. Sin un análisis exhaustivo de todas estas leyes, remito a Peralta Abogados, Guía sobre incentivos tributarios a donaciones, 2018, documento disponible en [https://irade.cl/wp-content/uploads/2018/11/ guia-donaciones-2018.pdf] [visitado el 14 de mayo de 2019]. Para un estudio de las distintas fuentes, CAlderón Torres, P. "Beneficios tributarios por donaciones", Revista de Estudios Tributarios, n. ${ }^{\circ} 1$, 2010, 97-131, disponible en [https://revistaestudiostributarios.uchile.cl/index.php/RET/article/ view/41234/42769] [consultado el 14 de mayo de 2019]. Sobre la aplicación práctica de estos tributos, ID., "Aplicación práctica de los beneficios tributarios a las donaciones", Revista de Estudios Tributarios, n. ${ }^{\circ} 4,2011,85-121$, disponible en [https://revistaestudiostributarios.uchile.cl/index. $\mathrm{php/RET/article/download/41146/42684/]} \mathrm{[consultado} \mathrm{el} 14$ de mayo de 2019].

19 Saffie Gatica, F., "El impuesto a las herencias como una institución de justicia", Estudios Públicos, n. ${ }^{\circ} 126,2012$, 126-161, disponible en [www.cepchile.cl/cep/site/docs/20160304/20160304095919/ rev126_FSaffie.pdf] [consultado el 30 de enero de 2020].

20 Vid. el artículo 19, n. ${ }^{\circ}$ 24, del Texto Refundido, Coordinado y Sistematizado de la Constitución Política de la República de Chile, modificada por última vez el 24 de diciembre de 2019 por la ley n. ${ }^{\circ}$ 21.200. Texto íntegro disponible en [www.leychile.cl/Navegar?idNorma=242302] [consultado el 30 de enero de 2020]. 
impuesto para donaciones con determinado objeto, mas no para herencias. El tramo exento equivale aproximadamente a 29.000.000 de pesos; es decir, unos 42.000 dólares o 35.000 libras esterlinas. Por mucho que se multiplique por número de asignaciones, esta porción exenta no se compara con los 11 millones de dólares a que asciende la cuantía exenta de una herencia en Estados Unidos; ni con 325.000,00 libras esterlinas, aplicable en el Reino Unido ${ }^{21}$.

A pesar de las fuertes atribuciones antielusión que sucesivas reformas legales han ido entregando al Servicio de Impuestos Internos, el impacto recaudatorio del impuesto a las herencias y donaciones es bajo. En el año 2015 la recaudación fue del $0,3 \%$ del total en el país, manteniéndose en el mismo rango al año siguiente. En los mismos períodos otros impuestos recaudaron considerablemente más. Por ejemplo, el de la ley de la renta ${ }^{22}$ recaudó más del $40 \%$ del total y el IVA ${ }^{23}$ hasta un $49 \%{ }^{[24]}$. Si esto es indicativo de algo, nos inclinamos a pensar que es debido a que pocos son los bienes que se transmiten por causa de muerte o entre vivos por mera liberalidad. Esto también levanta especulaciones sobre la extensión que podrían tener en la práctica las ordenaciones sucesorias realizadas entre vivos, a través de sociedades u otros instrumentos. La pregunta es: ¿por qué no dejar que el testamento ordene? Opinamos que la libre circulación de la propiedad también autoriza su transmisión por causa de muerte o a través de otras liberalidades. La garantía constitucional del derecho de propiedad sobre toda clase de bienes (artículo 19, número 24 CPR) asegura la libertad de disposición entre vivos y por causa de muerte. Si bien la derogación de la ley sobre impuesto a las herencias y donaciones es un tema que excede el objeto de este estudio, se puede considerar sin embargo que, en atención a las figuras citadas, esta no produciría un impacto serio en la recaudación fiscal total.

\section{Indicios sobre el escaso uso del testamento}

Todos los factores anteriormente expuestos estarían relacionados con el escaso uso del testamento como instrumento de ordenación sucesoria, lo cual puede inferirse a

21 Weidenslaufer von Kretschmann, $\mathrm{CH}$. y Cavada Herrera, J. P, Impuesto a las herencias en Chile, Reino Unido y EE.UU., Valparaíso, Biblioteca del Congreso Nacional, Asesoría Técnica Legislativa, Sup: 236066, 2018, 1-11, disponible en [www.bcn.cl/obtienearchivo?id=repositorio/10221/26779/2/ Impuesto_herencias_comparado.pdf] [consultado el 30 de enero de 2020].

22 D. L. n. ${ }^{\circ} 824$, que aprueba texto que indica de la Ley de Impuesto a la Renta, promulgado el 27 de diciembre de 1974 y publicado en el Diario Oficial el 31 de diciembre de 1974, modificado por última vez por el Decreto Exento n. ${ }^{\circ} 31$ del 6 de febrero de 2019. Texto íntegro disponible en [www. leychile.cl/Navegar?idNorma=6368\&idVersion=2014-05-01] [consultado el 30 de enero de 2020].

23 D. L. n. ${ }^{\circ} 825$, sobre impuesto a las ventas y servicios, de 1975, modificado por última vez por la ley n. ${ }^{\circ} 21.203$, del 21 de enero de 2020. Texto íntegro disponible en [www.leychile.cl/Navegar?idNor ma=6369] [consultado el 30 de enero de 2020].

24 Información disponible en [www.sii.cl/aprenda_sobre_impuestos/estudios/estadistribu/ingresos_tri butarios_new.htm] [visitado el 30 de abril de 2019]. El IVA es el impuesto de mayor recaudación en Chile, seguido por el que grava a la renta. La recaudación fiscal total se integra con otras leyes que en su conjunto no recaudan más del $20 \%$ del total. 
partir de algunos indicadores. Por ejemplo, en el año 2015 ingresaron a tramitación judicial 2666 solicitudes de posesión efectiva de herencias testadas en todo el país ${ }^{25}$. Ese mismo año se produjeron 103.000 defunciones y se inscribieron 62.283 resoluciones de posesiones efectivas de herencias intestadas. Las figuras no experimentan muchas alteraciones de año en año: en 2016 ingresaron 2871 solicitudes de posesión efectiva de herencias testadas, mientras que se registraron 104.026 defunciones y se inscribieron 75.198 resoluciones de posesión efectiva de herencia intestada ${ }^{26}$. Traduciendo estas cifras a términos comparables, pueden estimarse en unas 25 las herencias testadas por cada 1000 difuntos en Chile.

Otro indicador del escaso uso del testamento es el número de los que se inscriben cada año en el Registro Nacional de Testamentos ${ }^{27}$. En el año 2015 se registraron 6748 testamentos otorgados en todo el territorio de la República. Entre los años 2016 y 2018 la cifra se mantiene en torno a los 6700 testamentos $^{28}$.

La pregunta es cómo corregir esta situación para que el testamento vuelva a ser un instrumento que permita la disposición de bienes por causa de muerte a favor de legitimarios, como también a favor de quienes no lo sean. ¿Cómo evitar que los bienes se transmitan por actos más o menos simulados entre vivos? ¿Cómo devolver al causante la facultad de disponer libremente de lo suyo para después de sus días? Creemos que una medida de gran eficacia sería la derogación de la cuarta de mejoras, idea que se desarrolla a continuación.

25 La posesión efectiva de herencias intestadas se otorga por resolución administrativa de la Dirección Nacional del Registro Civil. La posesión efectiva de herencias testadas sigue siendo necesario requerirla al juez del último domicilio del causante. Consúltese la Ley $n .^{\circ} 19.903$, sobre procedimiento para el otorgamiento de la posesión efectiva de la herencia y adecuaciones de la normativa procesal, civil y tributaria sobre la materia, promulgada el 9 de septiembre de 2003 y publicada en el Diario Oficial el 10 de octubre de 2003 (versión única), en sus artículos 1. y 5. . Texto íntegro disponible en [www.leychile.cl/Navegar?idNorma=215613\&r=2] [consultado el 30 de enero de 2020].

26 Las figuras están tomadas de información estadística disponible al público general. Cf. Informe Anual de Justicia 2016, disponible en [www.ine.cl/docs/default-source/sociales/justicia/informeanual-de-justicia-2016.pdf?sfvrsn=4]. Departamento de Estadísticas e Información de Salud, disponible en [www.deis.cl/wp-content/2017/gobCL-sitios-1.0/assets/SerieDefunciones_2000_2015. html] [visitados el 30 de abril de 2019]. La información sobre posesiones efectivas intestadas fue proporcionada a la autora por ley de transparencia (Carta SDPE $n .^{\circ}$ 185-2019). En el mismo sentido, con datos anteriores, SuAu Cot, V., La libertad de testar y sus límites: hacia una reforma de las asignaciones forzosas, Facultad de Derecho, Universidad de Chile, tesis para optar al grado académico de licenciada en Ciencias Jurídicas y Sociales, Santiago, 2015, 82-84. Texto íntegro disponible en [http://repositorio.uchile.cl/ bitstream/handle/2250/133419/La-libertad-de-testar-ysus-1\%EDmites-hacia-una-reforma-de-las-asignaciones-forzosas.pdf?sequence=1] [consultado el 8 de mayo de 2019].

27 El Registro Nacional de Testamentos se forma a partir de la ley n. ${ }^{\circ} 19.903$ en su artículo $13 .{ }^{\circ}$, con la nómina de testamentos, otorgados o protocolizados ante sí, enviada por los notarios de todo el territorio nacional al Servicio de Registro Civil e Identificación. Vid. nota 25.

28 Información proporcionada a la autora por ley de transparencia (Carta SDPE n. ${ }^{\circ}$ 185-2019). 


\section{La cuarta de mejoras y su urgente derogación}

Una forma de corregir el sobredimensionamiento de las asignaciones forzosas consiste en derogar la cuarta de mejoras ${ }^{29}$. La derogación de la cuarta de mejoras se justifica por su origen y posterior transformación en el sistema sucesorio chileno. Su directa eliminación produce el inmediato efecto de liberar la mitad de acervo hereditario para disposiciones de libre voluntad.

\section{A. La construcción histórica de la cuarta chilena de mejoras}

La cuarta de mejoras es, en el Código Civil chileno, una mejora sui generis. Es decir, que no responde a su lógica histórica y que ha experimentado una evolución contradictoria con el concepto mismo de las asignaciones forzosas. En las líneas que siguen se procura explicar cómo es que se produce este fenómeno.

El redactor del Código Civil chileno consideró que no eran necesarias asignaciones forzosas para que los padres pudieran disponer de bienes a favor de sus hijos ${ }^{30}$. Admitiendo las legítimas, en su proyecto para este cuerpo normativo procura plegarse a una mayoría en la Comisión Revisora. No se muestra igualmente condescendiente con la mejora, institución que califica como "invención peculiar de los godos", que se prestaba, a su juicio, para enmarañadas discusiones en los autores españoles $^{31}$. Por esta razón en los proyectos de 1841,1846 y 1853 no existe siquiera un concepto de ella. La Comisión Revisora del Proyecto de 185e, sin embargo, decide reintroducirla, pues era derecho vigente de la época. Sin embargo, opta por excluirla de "la porción de bienes de que el difunto ha podido disponer a su arbitrio" (artículo 1.184, inciso $2 .^{\circ}$, al final). Como consecuencia, cada vez que sobrevive al causante un asignatario de mejora, se reduce esta última porción a una cuarta parte del acervo. Esta última es la porción de bienes de que el causante "ha podido disponer a su arbitrio". Así se explica que el inciso 3. ${ }^{\circ}$ del actual artículo 1.184 aparezca por primera vez en el Proyecto Inédito (artículo 1.345, inciso $\left.3 .^{\circ}\right)^{32}$. Solo entonces adquiere sentido la singular expresión "la mitad restante es la porción de bienes de

29 Esta medida ha sido propuesta por una moción parlamentaria. Cf. Boletín n. ${ }^{\circ}$ 12.301-07, ingresado el 11 de diciembre de 2018; en primer trámite constitucional en el Senado de la República de Chile (Comisión de Constitución y Justicia), en adelante, el proyecto de ley (PL). El resumen de la tramitación puede encontrarse en [www.camara.cl/pley/pley_detalle.aspx?prmID=13555\&prmBOLE TIN=13013-07] [consultado el 30 de enero de 2020].

30 "En el corazón de los padres tiene el interés de los descendientes una garantía mucho más eficaz que la protección de la ley.” Bello, A., Obras completas, Amunátegui Reyes, M. L. (ed.), Santiago, Imprenta de P. Ramírez G., 1881, vol. II, p. 80.

31 Ibid., vol. viI, p. 358. Para un estudio completo de la mejora en el Derecho español, AlBaladeJo García, M., La mejora, Madrid, Colegio de Registradores de la Propiedad, 2003.

32 Un resumen del proceso de elaboración del Código Civil chileno, recientemente revisado, puede encontrarse en Corral Talciani, H., Curso de Derecho Civil. Parte general, Santiago, Legal Publishing Chile, 2018, 213-218. 
que el difundo ha podido disponer a su arbitrio", que pertenece al texto original del Código y no ha experimentado modificaciones en las sucesivas reformas que ha tenido dicho artículo ${ }^{33}$.

La mejora testamentaria chilena resulta ser muy distinta a la institución que se conocía entonces. Después de una compleja evolución ${ }^{34}$, en el derecho castellano la parte de mejoras era de un tercio. El tercio se extraía de las cuatro quintas partes del acervo que se destinaba a pagar las legítimas ("legítima española"). El testador podía disponer de una quinta parte de sus bienes para asignaciones de libre disposición. La parte de mejoras era una porción de la legítima que el testador podía asignar a uno o más de sus descendientes legítimos, fueran o no legitimarios. El testador podía, por ejemplo, favorecer a un nieto con el tercio y el quinto. Así se hablaba de mejorar con tercio y quinto. Claro Solar cita a pie de página un pasaje del Quijote en que se narra que Sancho Panza "puso su jumento a las mil lindezas, dejándole mejorado en quinto y tercio" 35 .

En el Código Civil de 1855, y hasta la reforma de la ley n..$^{\circ} 18.802$, la cuarta de mejoras tenía por asignatarios únicamente a descendientes del testador, fueran legitimarios o no. Es decir, incluso considerada su cuantía, la desnaturalización de la mejora empieza con la ley que instituye al cónyuge sobreviviente como asignatario forzoso de cuarta de mejoras ${ }^{36}$. Con esta reforma se rompe la lógica de que las mejoras sean disposiciones testamentarias a favor de descendientes, fueran o no legitimarios. Ocurre esto al autorizar una disposición horizontal de parte del caudal relicto, que de otro modo se trasmitiría en la línea de la descendencia. La porción conyugal, como se llamaba entonces, era todavía incompatible con lo que el cónyuge lleva por gananciales de la sociedad conyugal, con sus bienes propios y con lo que lleva abintestato (dependiendo de si concurre o no con ascendientes del causante). Lo que ocurre después afirma, a nuestro juicio, la necesidad de una reforma.

\section{B. Expansión posterior contradictoria}

La ley n. ${ }^{\circ} 19.585$ instituye a los ascendientes como asignatarios forzosos de dicha porción, volviendo a modificar el Código Civil en su artículo 1.184 , inciso $3 .^{\circ}$. Como resultado de estas modificaciones se forma cuarta de mejoras aunque no haya hijos ni descendencia con derecho a representarlos, e incluso aunque no haya cónyuge ni, a partir de la ley n..$^{\circ} 20.830$, conviviente civil sobreviviente ${ }^{37}$. Así se concluye del texto del artículo en cuestión, donde se lee: "Habiendo tales descendientes, cónyuge

33 Claro Solar, L., Explicaciones de Derecho Civil chileno y comparado, op. cit., n. ${ }^{\circ} 1539$.

34 Ibid., n. ${ }^{\circ} 1540$.

35 Ibid., n. 1540 , nota 93 al pie (énfasis del autor).

36 Artículo $1 .^{\circ}$, número 51 de la ley n. ${ }^{\circ} 18.802$, de 1989.

37 Vid. nota 17. 
o ascendientes, la masa de bienes [...] se dividirá en cuatro partes: dos de ellas, o sea, la mitad del acervo, para las legítimas rigorosas; otra cuarta, para las mejoras con que el difunto haya querido favorecer a su cónyuge o a uno o más de sus descendientes o ascendientes, sean o no legitimarios, y otra cuarta, de que ha podido disponer a su arbitrio" (énfasis agregado). Como la cuarta de mejoras se deduce de la parte de libre disposición, sucede que la parte del acervo que el testador debe reservar para legitimarios y asignatarios forzosos de mejora alcanza a las tres cuartas partes ${ }^{38}$.

En definitiva, el único supuesto en que un testador puede disponer en Chile de más de una cuarta parte de sus bienes a través de disposiciones testamentarias a favor de parientes o extraños sería que no sobrevivan al causante legitimarios ni asignatarios forzosos de mejoras que no sean legitimarios. Es decir, ningún descendiente, ningún ascendiente, ni cónyuge o conviviente civil. Solo a partir del tercer orden de sucesión intestada, en que la ley llama a los hermanos del difunto (artículo 990), el causante de una herencia ha podido disponer libremente de sus bienes. Se observa, entonces, cómo en su origen y evolución posterior, la cuarta de mejoras es un límite considerable a la libertad de disposición de bienes por causa de muerte, adicional a la legítima porque que no es parte de esta ${ }^{39}$.

38 Algunos ejemplos sirven para ilustrar este problema. 1. : Si sobreviven al difunto hijos y cónyuge sobreviviente, éstos llevan la mitad legitimaria (artículos 1.183,889 c.c.ch.), dos de las cuatro partes en que se divide la herencia (artículo 1.184 c. c. ch.). Los hijos y el cónyuge sobreviviente son, además, asignatarios forzosos de "las mejoras con que el difunto haya querido favorecer a su cónyuge o a uno o más de sus descendientes o ascendientes, sean o no legitimarios" (artículo 1.184, inciso $3 .^{\circ}$ c. c. ch.). Si el difunto no ha querido o podido disponer de esta cuarta parte, ella acrece a la mitad legitimaria incrementando su cuantía hasta las tres cuartas partes de la herencia (artículo 1.191 c. c. ch.). Por este acrecimiento que experimenta la legítima, los legitimarios disponen de tres cuartas partes del caudal hereditario para legítimas rigorosas y efectivas. Haya o no dispuesto efectivamente de la cuarta de mejoras, en este escenario el difunto sólo ha podido disponer libremente de una cuarta parte de sus bienes. $2 .^{\circ}$ : Si sobreviven al causante hijos de un anterior matrimonio, conviviente civil, padres y abuelos, los ascendientes quedan excluidos de la legítima (artículo 1.183 c. c. ch.). Si el causante no dispuso por testamento de la parte de mejoras, ésta acrece a la mitad de las legítimas (artículo 1.191 c. c. ch.); con lo que resulta que tres cuartas partes del caudal hereditario queda reservado para las legítimas rigorosas y efectivas de los hijos y del conviviente civil sobreviviente. El causante solo ha podido disponer libremente de una cuarta parte de sus bienes. $3 .^{\circ}: \mathrm{Si}$ al causante no lo sobreviven hijos, ni descendencia que los represente, ni cónyuge sobreviviente, ni conviviente civil sobreviviente, los ascendientes que sobrevivan llevan tres cuartas partes del caudal hereditario a título de legítima rigorosa o efectiva, según si el causante dispuso o no de la cuarta de mejoras por testamento, de la que sólo ellos son asignatarios forzosos (artículos 1.183, 989, 1.184 c. c. ch.). El difunto sólo ha podido disponer libremente de una cuarta parte de sus bienes.

39 Así se explica la propuesta de "mejorar la mejora" conservando su cuantía, pero modificando su origen, autorizando que pueda destinarse a mejoras hasta la mitad de la legítima. CorRAL TALCIANI, H., "Derecho sucesorio: ¿eliminar o mejorar la mejora?", columna de opinión, 2011, disponible en [https://corraltalciani.wordpress.com/2011/02/14/derecho-sucesorio-\%C2\%BFeliminar-o-mejorarla-mejora/] [visitado el 14 de mayo de 2019]. El autor afirma que esta medida evitaría el riesgo de desequilibrar el actual sistema sucesorio chileno que ha funcionado por más de un siglo sin mayores problemas. 


\section{La urgente derogación de la cuarta de mejoras}

La medida correctiva que se propone es derogar la cuarta de mejoras ${ }^{40}$. Su eliminación dispensaría la mitad del caudal hereditario para disposiciones de libre voluntad. Sin cuarta de mejoras, el testador podría igualmente mejorar con la parte de libre disposición (que pasaría a ser la mitad del acervo hereditario) al cónyuge y demás parientes que desee, incluidos los que ahora son asignatarios forzosos de mejoras. Además, la parte de legítimas volvería a su proporción histórica: la mitad del caudal hereditario, como lo previó Bello originalmente (artículo 1.345 del Proyecto de 1853), como era en el derecho romano justinianeo reflejado en Las siete partidas.

Para lograr estos efectos, habría que eliminar unas pocas disposiciones del Título v del Libro III del Código Civil ("De las asignaciones forzosas"). En concreto: el artículo 1.167, n. $^{\circ} 3$ (que establece la mejora como asignación forzosa) ${ }^{41}$; el artículo 1.184 , inc. $3 .^{\circ}$ o final, que instituye las consabidas cuartas en que se divide el acervo para su distribución entre asignatarios forzosos ${ }^{42}$; el artículo 1.194 (que establece la preferencia de que goza la mejora para su pago); el artículo 1.195 (que establece que de la mejora puede hacer el testador la distribución que quiera) ${ }^{43}$; y el artículo 1.204 (que regula el pacto de no mejorar) ${ }^{44}$. En los demás artículos de este título y en otras partes del Libro III del Código habría que eliminar toda referencia a la mejora ${ }^{45}$. La derogación del inciso $3 .^{\circ}$ del artículo 1.184 , además, dirime por eliminación la controversia acerca de la formación de esta porción de mejoras fuera del orden de los descendientes legítimos ${ }^{46}$.

40 En este mismo sentido, SuAu Cot, V. La libertad de testar y sus límites: hacia una reforma de las asignaciones forzosas, op. cit., 105. También, Varas Braun, J. A., "Uniones de Hecho y Derecho Sucesorio (Libertad de testar para solteros sin hijos)", Revista de Derecho (Valdivia), vol. xxIII, n. ${ }^{\circ}$ 2, 2010, 9-22, disponible en [https://scielo.conicyt.cl/pdf/revider/v23n2/art01.pdf] [consultado el 30 de enero de 2020].

41 Así se propone también en el PL Boletín n. ${ }^{\circ}$ 12.301-07, artículo 2..

42 PL Boletín 12.301-07, artículo 3. ${ }^{\circ}$, numeral 2.

43 Así lo propone también el artículo 3.․, numeral 9 del PL. Se promueve además la derogación del actual artículo 1196, que ordena rebajar proporcionalmente las legítimas y mejoras cuando no alcanzan los bienes del acervo para su entero. Sin embargo, en esta norma solo habría que eliminar la referencia a la mejora puesto que se mantendría la legítima en su configuración actual.

44 El PL propone además la derogación del artículo 1.201 (imputación a la mejora de donaciones hechas a título de mejora); y el inciso $2 .^{\circ}$ y $3 .^{\circ}$ del artículo 1.203 (desembolsos hechos para el pago de las deudas de un legitimario que podían imputarse a su mejora).

45 Casi todas estas referencias se eliminan en el PL, en actual trámite. Vid. nota 29.

46 A partir de la ley n. ${ }^{\circ} 10.271$, de 1952, la doctrina chilena discutió si se formaba cuarta de mejoras en presencia de hijos naturales, o si sólo se formaba en presencia de hijos legítimos, aunque los primeros fueran asignatarios de mejora. Cf. Alessandri Rodríguez, A., Reformas introducidas al Código Civil por la Ley 10.271, Santiago, Ediar Editores, 1955, 49, donde opina que del tenor literal del inciso segundo del artículo 1184, el espíritu de la reforma y su concordancia con numerosas otras disposiciones permite concluir que se forma cuarta de mejoras aunque sólo haya hijos naturales o descendientes legítimos de éstos, sin que existan, además, descendientes legítimos del causante. En el mismo sentido, Somarriva Undurraga, M., Evolución del Código Civil chileno, Santiago, 
Esta propuesta considera que se puede mantener vigente todo el resto del sistema. Es decir, la orden de hacer deducciones y agregaciones para la formación de los acervos sobre los cuales se calcula la legítima (artículos 1.185 a 1.189); y las imputaciones que deben hacerse para el pago de la legítima (artículos 1.198 y 1.203). Asimismo mantiene la legítima de los hijos, personalmente o representados por su descendencia, en los términos que la contempla el derecho chileno, sin modificaciones cualitativas ni cuantitativas.

Colombia ha modificado recientemente su Código Civil para aumentar la libertad de testar, derogando también la cuarta de mejoras ${ }^{47}$. El nuevo artículo 1.226 elimina la mejora de la lista de asignaciones forzosas; y en el artículo 1.242, correlato del artículo 1.184 c. c. ch., esto se refleja disponiendo que se destine la mitad del acervo al entero de legítimas y que la otra mitad constituya "la porción de bienes de que el testador ha podido disponer a su arbitrio". En ese país la mejora también limitaba considerablemente la libertad de testar, pero ni el cónyuge ni los ascendientes eran asignatarios respecto de ella. Por otra parte, el cónyuge sólo tenía derecho a lo que era para nosotros -y sigue siendo en Colombia- "porción conyugal", es decir, una parte de bienes en la que se considera lo que le corresponde por gananciales de la sociedad conyugal y otros bienes que imputan a ella. El Código Civil colombiano no había experimentado las reformas que describimos en este artículo; sin embargo, la derogación de la cuarta de mejoras se tenía como una medida necesaria para ampliar la libertad de testar en el actual estado de cosas.

A continuación se explican las correcciones que deberían hacerse a la legítima de los ascendientes y a la legítima del cónyuge o conviviente civil sobreviviente.

\section{Correctivos a la legítima}

Derogada la cuarta de mejoras, la mitad del acervo hereditario quedaría para disposiciones de libre voluntad, y la otra se reservaría para el entero y pago de su legítima a los que tienen derecho a ella. Estos son, actualmente, los hijos (personalmente o representados por su descendencia), los ascendientes y el cónyuge o conviviente civil sobreviviente ${ }^{48}$. En la misma línea y por las mismas razones que justifican tal derogación, dejando a salvo la calidad y cuantía de la legítima de los hijos, personalmente

o representados por su descendencia ${ }^{49}$, debería reducirse la calidad de la legítima

Editorial Nascimento, 1955, 267. Sostiene la opinión contraria, por ejemplo, RodríGuez Grez, P., Instituciones de Derecho Sucesorio, op. cit., 302.

47 Ley n. ${ }^{\circ} 1.934$, del 2 de agosto de 2018, por medio de la cual se reforma y adiciona el Código Civil Texto íntegro disponible en [http://es.presidencia.gov.co/normativa/normativa/LEY\%201934\%20 DEL\%2002\%20DE\%20AGOSTO\%20DE\%202018.pdf] [consultado el 30 de enero de 2020].

48 Artículo 1.182 c. c. ch.; artículo 16 de la ley n. ${ }^{\circ} 20.830$.

49 En línea con los cambios que ha experimentado el derecho sucesorio en otros países, se ha propuesto cambiar la edad o calidad para que hijos y descendientes sean legitimarios. Barría Paredes, M., Asignaciones forzosas y libertad de testar, op. cit., 243-254. En cambio, Suau Cot, V., La libertad 
de los ascendientes y del cónyuge o conviviente civil sobreviviente. Esto es lo que explicamos en lo que sigue de este estudio.

\section{A. Los ascendientes como legitimarios}

Los ascendientes son llamados como legitimarios si no hay descendencia ${ }^{50}$. En este caso, la legítima se reparte entre los ascendientes y el cónyuge ${ }^{51}$ o conviviente civil ${ }^{52}$ sobreviviente ${ }^{53}$. Cuantitativamente, la legítima es la mitad de los bienes (previas deducciones y agregaciones legales) ${ }^{54}$. En el derecho romano que recibe Occidente la cuantía de esta parte no pasaba de la mitad de los bienes en que se sucedía al causante. Se comprende que Bello haya aceptado cuantificar la legítima en la mitad del acervo hereditario, y no en más ${ }^{55}$.

La legítima se mantiene en su cuantía aunque no haya descendencia, ni cónyuge o conviviente civil sobreviviente, y solo sean llamados uno o más ascendientes del

de testar y sus límites: hacia una reforma de las asignaciones forzosas, op. cit., 132 propone que esta legítima no se modifique. En este trabajo proponemos no tocar ni la cantidad ni la cuantía de la legítima de los descendientes. Para las condiciones en que estos alimentarios llevan alimentos como asignación forzosa, me remito al tratamiento general de los manuales. Por todos, después de las más recientes reformas, Elorriaga DE Bonis, F., Derecho Sucesorio, Santiago, Legal Publishing Chile, 2015, 443-450.

50 Artículo 1183 c. c. ch.

51 Artículo 989 c. c. ch.

52 Artículo 16 de la ley n. 20.830.

53 Si concurren ascendientes con cónyuge o conviviente civil, el acervo se divide en tres partes. Dos para el cónyuge o conviviente civil sobreviviente; y una para los ascendientes de grado más próximo. A falta de ascendientes, lleva todo el cónyuge o conviviente civil sobreviviente. A falta de cónyuge o conviviente civil, llevarán todos los ascendientes de grado más próximo, o el único que sobreviva al causante en el grado más próximo (artículo 989 c. c. ch.).

54 Artículo 1.184, inciso 2. ${ }^{\circ}$ c. c. ch.

55 Las siete partidas fijaban la legítima en un tercio si había cuatro o menos hijos, y un medio si había cinco o más hijos. Se pasaba en silencio la institución de la mejora que no fue conocida por el Derecho Romano (Partida Sexta, Título 1, Ley 17). El Derecho romano parece haber introducido la legítima, más que a través de la cuarta falcidia (40 a. C.), mediante la querella de inoficioso testamento y la bonorum possessio contra tabulas. En el Tribunal de los Centumviri (s. II a. C.?) la querella la tuvieron los parientes más cercanos del testador a quienes no se había asignado al menos un cuarto de lo que les habría correspondido abintestato, para obtener no ese cuarto, sino su cuota intestada completa. Por otra parte, a partir del Edicto del Pretor (s. I a. C.), se concede al patrono y al padre que había manumitido a un hijo la bonorum possessio contra tabulas para obtener la mitad del acervo sucesorio, cuando el liberto o emancipado no les ha asignado esta cuota en su testamento, ni tiene liberi que lo sucedan. Por tanto, la parte de legítimas habría sido de una cuarta parte. Tenían derecho a ella los parientes más cercanos en grado al testador (a quienes se les concedía la querella de inoficioso testamento) y el patrono o padre de un hijo manumitido que no tiene liberi que lo sucedan (a quienes el pretor daba la bonorum possessio de esta parte del acervo contra tabulas). Sólo tardíamente, Justiniano aumenta la cuota legítima de un cuarto a un tercio; o a un medio, si concurrían más de cuatro hijos. Esto coincide con la legítima de Las siete partidas: un medio (Partida Sexta, Título I, Ley 17) o la mitad de la herencia. GuZMÁn BRITo, A., Derecho Privado Romano, Santiago, Editorial Jurídica de Chile, 2004, vol. II, 480; SAmPer Polo, F., Derecho Romano, Santander, Imprenta Guzmán, 1984, 225-229. 
causante. Es interesante observar esto porque la Partida Sexta, Título 13, Ley 8, fijaba la legítima de los ascendientes en un tercio del acervo hereditario; es decir, menos de un medio. El derecho castellano vigente en la época anterior al Código disponía que la legítima de los ascendientes fuera de dos tercios, más de un medio. Es decir, en la situación vigente antes del Código Civil, los ascendientes habían mejorado la cuantía de su legítima. Bello modificó la situación existente, equiparando la cuantía de la legítima de los ascendientes a la de los descendientes, es decir, a la mitad de la herencia (la mitad legitimaria). En un contexto sociológico diverso del actual, al revés de lo que era su idea en materia de mejoras, pensaba que la ley debía resguardar lo que no era el orden natural de los afectos. "Los padres necesitan de la protección de la ley", escribía Bello en nota al inciso 2. ${ }^{\circ}$ del artículo 1.345 del Proyecto de 1841 , en tanto que "los hijos apenas la han menester" 56.

La presencia de ascendientes entre los legitimarios está en nuestra legislación desde el Código Civil de 1855. Esto ha despertado poco interés, probablemente, porque los ascendientes solo son llamados como legitimarios cuando falta descendencia (artículos 1.183 y 989). Los cambios se han producido en la expectativa de vida de las personas, por lo que es poco probable que hoy un ascendiente sobreviva a un causante de larga vida. La legítima de los ascendientes es infrecuente. Por este motivo pensamos que un ascendiente solo debería ser llamado como legitimario si necesita la herencia que se le defiere. Derogada la cuarta de mejoras, la segunda de las reformas que debería hacerse al derecho sucesorio debería consistir en reducir la cuantía de la legítima de los ascendientes o en transformar su calidad.

\section{B. Una legítima reducida o alimentaria para los ascendientes}

Reducir la cuantía de la legítima de los ascendientes consistiría, por ejemplo, en reducir a un cuarto del acervo hereditario la porción de bienes que forzosamente deban reservárseles, dejando para disposiciones de libre voluntad el resto de los bienes transmisibles. Reducida a un cuarto la legítima de los ascendientes, el causante a quien no sobreviven descendientes ni cónyuge o conviviente civil puede disponer libremente por testamento de $3 / 4$ partes de sus bienes.

La otra alternativa consiste en mantener la legítima en un medio del acervo, pero modificar la calidad de su legítima, asimilándola a una de carácter alimentaria, como era en Chile la porción conyugal. Para esto se podría agregar al artículo 1.182 un inciso que podría decir lo siguiente: "Si el o los ascendientes tuvieren bienes, pero no de tanto valor como lo que les corresponde en la herencia por legítima rigorosa, solo tendrán derecho al complemento a título de legítima". Esta solución protege a los

56 Bello, Obras completas, op. cit., vol. II, 81. En el Derecho castellano los ascendientes no eran asignatarios de mejora; ni lo fueron en el Código Civil chileno sino hasta la ley n. ${ }^{\circ} 19.585$, de 1998. La mejora se destinaba exclusivamente a la descendencia legítima. Claro Solar, Explicaciones de Derecho Civil chileno y comparado, op. cit., n. ${ }^{\circ} 1445$. 
ascendientes que necesitan esta asignación, respetando a la vez la facultad de disponer de un causante sin descendencia, ni cónyuge, ni conviviente civil sobrevivientes.

Esta legítima alimentaria podría ser compatible con asignaciones testamentarias con cargo a la parte de libre disposición, sin perjuicio de que se respeten las imputaciones que exige el artículo 996 c. c. ch. Es decir, guardando la norma que dispone que se imputen las asignaciones testamentarias a lo que se tiene derecho abintestato, quedando a salvo el derecho del asignatario de retener las porciones testamentarias si son mayores que las que le corresponden por ley. Para conseguir esto, los ascendientes deberían ser obligados a imputar a su legítima el valor de su patrimonio, y no solamente lo que reciben por liberalidad testamentaria en la sucesión. En consecuencia, llevarían herencia exclusivamente si la cuantía de sus bienes es inferior a lo que les cabe en la herencia como legítima rigorosa y, en este caso, solo llevarían el complemento. La porción de bienes de que el difunto ha podido disponer libremente sería la mitad del acervo hereditario con los aumentos que pueda experimentar por rebajas a la cuantía de la legítima (alimentaria) de los ascendientes.

El testador podría disponer libremente de la mitad del acervo hereditario, también en favor de sus ascendientes. Por otra parte, esta porción de bienes se vería aumentada por las sumas que se liberen por rebajas que deban practicarse a la legítima de los ascendientes.

Retocada en una u otra forma la legítima de los ascendientes, quedaría por corregir lo que actualmente en Chile es la "legítima privilegiada" del cónyuge o conviviente civil sobreviviente.

\section{De porción conyugal a legítima privilegiada}

En el Código Civil de 1855 la porción conyugal era "aquella parte del patrimonio de una persona difunta, que la ley asigna al cónyuge sobreviviente, que carece de lo necesario para su congrua sustentación" ${ }^{, 57}$. Esta era incompatible con los bienes propios del cónyuge sobreviviente, con los gananciales de la sociedad conyugal y con asignaciones del testamento del causante ${ }^{58}$. Ahora bien: no habiendo descendientes, la parte de la que el testador podía disponer libremente era la mitad de la herencia, y la porción conyugal una baja general ${ }^{59}$. A partir de la ley n. ${ }^{\circ} 10.271$, de $1952^{[60]}$,

57 Artículo 1.172 c. c. ch., derogado por la ley n. ${ }^{\circ} 19.585$ de 1998.

58 Según el artículo 1.176 c. c. ch. (derogado), si el cónyuge sobreviviente tuviere bienes, pero no de tanto valor como la porción conyugal, sólo tendrá derecho al complemento, a título de porción conyugal. Se imputará por tanto a la porción conyugal todo lo que el cónyuge sobreviviente tuviere derecho a percibir a cualquier otro título en la sucesión del difunto, inclusa su mitad de gananciales, si no la renunciare.

59 Artículo 959 c.c. ch.

60 Ley n. ${ }^{\circ}$ 10.271, que introduce diversas modificaciones en el Código Civil, promulgada el 29 de febrero de 1952 y publicada en el Diario Oficial el 2 de abril de 1952 (versión única). Texto íntegro disponible en [www.leychile.cl/Navegar?idNorma=26332] [consultado el 30 de enero de 2020]. 
concurriendo con hijos legítimos se aumenta la cuantía de la porción conyugal al doble de la legítima rigorosa de un hijo, y se hace compatible esta porción con asignaciones testamentarias hechas con cargo a la cuarta de libre disposición. Por otra parte, el cónyuge sobreviviente comienza a adquirir derechos de heredero, como el de solicitar la posesión efectiva de la herencia y el de pedir la partición y a intervenir en ella. La porción conyugal experimenta un nuevo aumento de cuantía con la ley $n .^{\circ} 18.802$, pues se dispone que esta sea el doble de lo que por legítima efectiva corresponde a un hijo, compatible, a partir de esta ley, incluso con lo que el testador pueda haber dejado al cónyuge a título de mejora.

La ley n. 19.585 se encuentra, por tanto, con un cónyuge sobreviviente que ya es un interesado prominente en la herencia del causante. El siguiente paso es simplemente reconocer lo que de hecho ocurre: el cónyuge es heredero. Se deroga, en consecuencia, la porción conyugal y todo su bagaje conceptual para reconocer al cónyuge sobreviviente, directamente, una legítima en la herencia, cualquiera sea la situación de éste como resultado del régimen matrimonial que tenía con el causante. Sin embargo, el cónyuge se transforma en un legitimario con porción garantizada en la herencia, pues ya no recibe una parte eventual como porción conyugal, en función de la cuantía de su patrimonio personal (bienes propios, gananciales de la sociedad conyugal o crédito por gananciales del régimen de partición y asignaciones en el testamento del causante) ${ }^{61}$. A partir, entonces, de la ley a que nos referimos, el cónyuge lleva el doble de la legítima rigorosa o efectiva de un hijo (matrimonial o no matrimonial, suyo o ajeno), con un mínimo que no puede bajar de "la cuarta parte de la herencia, o de la cuarta parte de la mitad legitimaria en su caso"62).

Además de sus bienes propios, el cónyuge sobreviviente puede llevar la mitad de gananciales $^{63}$, la cuarta de libre disposición, la cuarta de mejoras y la cuarta parte de la mitad legitimaria ${ }^{64}$. Lo que convierte la situación del cónyuge sobreviviente en un privilegio es que todos estos derechos o asignaciones son compatibles entre sí, y que además el cónyuge tiene un derecho preferente a pedir la adjudicación en propiedad de la vivienda que fue residencia principal de la familia y los muebles que la guarnecen en la partición de los gananciales y de la herencia, o derechos gratuitos de uso y habitación sobre ella. Es decir, en caso de no ser suficiente el haber del cónyuge para que se

61 Barría Paredes, M., Asignaciones forzosas y libertad de testar, op. cit., 255-265. El autor demuestra que al reconocer al cónyuge como legitimario en la herencia, el legislador de 1998 no considera el régimen matrimonial a que estaba sujeto, como sí hacía el sistema de porción conyugal. También destaca que en la discusión de dicha ley, una indicación parlamentaria que proponía que el derecho de adjudicación preferente fuera sobre la cuota de gananciales de la sociedad conyugal no prospera. A esta observación puede agregarse que tampoco se considera el divorcio, que se introdujo en Chile por ley n. ${ }^{\circ} 19.947$, de 2004, posterior a la discusión sobre la situación sucesoria del cónyuge sobreviviente.

62 Artículo 988, inciso $3 .^{\circ}$, c. c. ch. Sustituido como se presenta en el texto por el n. ${ }^{\circ} 75$ del artículo $1 .^{\circ}$ de la ley n. ${ }^{\circ} 19.585$, de 1998.

63 Artículo 1.774 c. c. ch.

64 Artículos 988 y 1.184 c. c. ch. 
le entere en propiedad la residencia principal de la familia y los muebles, tiene derecho a que se constituyan derechos gratuitos de uso y habitación sobre estos bienes ${ }^{65}$.

La opción del legislador por equiparar los derechos de los hijos no matrimoniales y matrimoniales se aseguró por un compromiso político-legislativo que consistió en mejorar la situación del cónyuge sobreviviente. De este modo, la familia matrimonial no se vería excesivamente perjudicada con respecto a los nuevos derechos que se reconocía a los hijos no matrimoniales. Si el cónyuge sobreviviente llevaba una porción privilegiada en la herencia (una legítima compatible con mejoras que el causante pudo haberle hecho en su testamento, con los gananciales que recibe en la liquidación de la sociedad conyugal y con sus bienes propios), los hijos matrimoniales mantenían la expectativa de heredar posteriormente a ese padre o madre con quien concurrían. Así, la herencia del cónyuge sobreviviente llegaba a lo que podríamos considerar su destino final, esto es, los hijos matrimoniales. Los hijos no matrimoniales llevaban su parte en la herencia, igual a la de un hijo (matrimonial); pero posteriormente no heredaban al cónyuge sobreviviente con quien habían concurrido en la herencia de su padre o madre.

La situación sucesoria privilegiada del cónyuge sobreviviente ya era excesiva antes de la ley de divorcio ${ }^{66}$. Con el término de la relación conyugal por medio de esta vía, los privilegios sucesorios del cónyuge sobreviviente podrían producir inequidades sucesorias ${ }^{67}$. Por ejemplo, a partir de entonces puede ocurrir que el cónyuge sobreviviente no sea padre o madre de los hijos del causante, con quienes concurre en el primer orden de sucesión intestada ${ }^{68}$ y en la mitad legitimaria ${ }^{69}$.

Con posterioridad, la ley n. ${ }^{\circ} 20.830$ atribuye al conviviente civil sobreviviente los mismos derechos que actualmente tiene el cónyuge de igual condición ${ }^{70}$. Por tanto, las situaciones de inequidad pueden darse en el caso de segundas o terceras nupcias del causante, por muerte o divorcio; y también en el caso de acuerdo de unión civil celebrado con posterioridad a la disolución de un matrimonio anterior. Esta inequidad consiste en que la mayor parte de los bienes del causante quedan en la

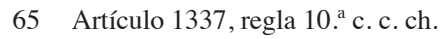

66 Ley n. $^{\circ} 19.947$, de 2004.

67 Un ejemplo común en el día de hoy. Si el cónyuge sobreviviente concurre con seis hijos de anteriores matrimonios del causante y ha sido instituido heredero de la cuarta de mejoras y de la cuarta de libre disposición, podría llevar: mitad de gananciales, cuarta de mejoras, cuarta de libre disposición y cuarta parte de la mitad legitimaria. Concurriendo con seis hijos del causante, conforme al artículo 988 c. c. ch., corresponderían al cónyuge sobreviviente dos octavas partes de la mitad legitimaria; es decir, una cuarta parte de dicha porción. Este cónyuge sobreviviente lleva hasta el 62,5\% del acervo hereditario, más su mitad de gananciales, sin perjuicio de sus bienes propios. Los seis hijos del causante (que no son, a la vez hijos suyos) se reparten por iguales partes el $37,5 \%$ del acervo hereditario a título de legítima rigorosa, y no tienen expectativa alguna en la herencia del cónyuge sobreviviente de su padre o madre.

68 Artículo 988 c.c.ch.

69 Artículos 1.183 y 1.184 c. c. ch.

70 Artículo 16 de la ley n. ${ }^{\circ} 20.830$. 
línea horizontal (cónyuge o conviviente civil sobreviviente) y no pasan a su descendencia, que es donde correspondería que lleguen forzosamente a título de legítima en la herencia de su padre o madre. Si los hijos con quienes concurre el cónyuge fueran también suyos (es decir, si el cónyuge concurriera con hijos comunes, suyos y del causante), esta inequidad se vería mitigada por la expectativa de los hijos de heredar posteriormente al padre o madre con quien ahora concurren. Mas si el cónyuge no es padre o madre de los descendientes del causante, los descendientes no tienen la expectativa de heredar al cónyuge o conviviente civil sobreviviente. La ley n. ${ }^{0} 19.585$ no tuvo presente un escenario de matrimonio disoluble por divorcio, como es lo que ocurre a partir de la ley n ${ }^{\circ} 19.947$, ni mucho menos podía concebir una ley que equipara los derechos hereditarios del cónyuge sobreviviente al sobreviviente de un acuerdo de unión civil.

\section{Una legítima rigorosa para el cónyuge sobreviviente}

Para reconducir en parte los bienes del causante a su descendencia y mitigar el efecto de segundas o terceras nupcias, o de un acuerdo de unión civil vigente, se propone reducir la legítima del cónyuge sobreviviente a la legítima rigorosa de un hijo del causante, sea éste descendiente suyo o no. Es decir, se propone que el cónyuge sobreviviente sea contado como un hijo más. Adicionalmente, se sugiere derogar la porción mínima que la ley asegura al cónyuge sobreviviente. Para reflejar estos cambios, el artículo 988 del Código Civil debería volver a su texto original: "Los hijos excluyen a todos los otros herederos, a menos que hubiere también cónyuge sobreviviente, caso en el cual éste concurrirá con aquéllos. El cónyuge sobreviviente recibirá una porción que, por regla general, será equivalente a lo que por legítima rigorosa corresponda a cada hijo. Si hubiere solo un hijo, la cuota del cónyuge será igual a la legítima rigorosa de ese hijo".

Uno de los beneficios de lo propuesto anteriormente sería el simplificar la comprensión del artículo 996 del Código Civil cuando quien hereda por testamento y abintestato es justamente el cónyuge sobreviviente. El artículo citado señala que los que suceden a la vez por testamento y abintestato imputen lo que reciben por testamento a su porción abintestato, sin perjuicio de retener toda la porción testamentaria, si excediere a la otra, prevaleciendo la voluntad del testador en lo que en derecho corresponda. Conforme con esta disposición, el cónyuge asignatario de disposiciones testamentarias deberá imputar esta asignación a lo que recibe abintestato, como legitimario. Parte importante de la doctrina, apoyada en el tenor literal del artículo, lo entiende de la manera señalada ${ }^{71}$. Pero hay lugar para interpretaciones en distinto sentido, al considerar que si el causante dejó parte de sus bienes al cónyuge por disposición testamentaria, ello fue a título de mejora respecto a su situación como heredero

71 Domínguez Benavente, R. y Domínguez Águila, R., Derecho Sucesorio, Santiago, op. cit., 723-731; Elorriaga de Bonis, F., Derecho sucesorio, op. cit., 363-370. 
legitimario, por lo que dicho cónyuge debería conservar la porción mínima que le garantiza la ley más la asignación testamentaria que no se imputa a dicha porción mínima $^{72}$. Eliminando la cuarta de mejoras y la porción o legítima mínima del cónyuge sobreviviente, no cabría duda de que estaría en la misma posición que el resto de los legitimarios, que deben imputar lo que reciben por legado a su legítima ${ }^{73}$. Por otra parte, derogada la cuarta de mejoras, no pueden hacerse donaciones o legados a título de mejoras: toda donación, herencia o legado a un legitimario se entiende a título de legítima, y debe imputarse a ella, salvo disposición expresa del testador en contrario. Es decir, todas las disposiciones testamentarias hechas a un legitimario (también el cónyuge) con cargo a la parte de libre disposición (que, derogada la cuarta de mejoras, es la mitad del acervo hereditario) se imputan a la legítima, salvo que el testador haya dispuesto expresamente otra cosa.

Lo que se propone iría en consonancia con códigos civiles recientemente modernizados, que aseguran la posteridad del cónyuge sobreviviente de una manera concorde con el principio de que los bienes se transmitan en la línea de la descendencia. En Argentina, por ejemplo, al concurrir con descendientes, siempre tiene en el acervo hereditario la misma parte que un hijo del causante ${ }^{74}$. Además, si concurre con los descendientes en la sucesión del causante, no tiene parte alguna en la división de los bienes gananciales de la sociedad conyugal ${ }^{75}$. Es decir, la porción que la ley le asegura al cónyuge sobreviviente en la herencia del causante es incompatible con los gananciales de la sociedad conyugal. En semejante sentido, no tiene derechos en la herencia del causante que fallece dentro de los treinta días de contraído el matrimonio, a consecuencia de enfermedad existente en el momento de la celebración, conocida por el supérstite, y de desenlace fatal previsible, excepto que el matrimonio sea precedido de una unión convivencial ${ }^{76}$. En Perú, "[e]l cónyuge que concurre con hijos o con otros descendientes del causante hereda una parte igual a la de un hijo"77, pudiendo optar por llevar el usufructo de un tercio de la herencia ${ }^{78}$.

\section{Conclusiones}

Según lo expuesto, se concluye que la libertad de disponer de bienes por testamento aumentaría mediante la derogación directa e inmediata de la institución de la cuarta

72 Corral Talciani, H., "Los nuevos órdenes de sucesión abintestato", en ID. (ed.), Derecho sucesorio actual y adjudicación de la vivienda familiar: Las reformas de la ley n. 19.585 de 1998, Santiago, Ediciones Universidad de los Andes, 2000, 42-44.

73 Artículo 1.198 c. c. ch.

74 Artículo 2.433 , inciso $1 .^{\circ}$, Código Civil y Comercial de la Nación.

75 Artículo 2433, inciso 2. ${ }^{\circ}$, Código Civil y Comercial de la Nación.

76 Artículo 2.436 Código Civil y Comercial de la Nación.

77 Artículo 822 Código Civil peruano.

78 Artículo 823 Código Civil peruano. 
de mejoras. El resultado sería que la mitad del acervo transmisible por causa de muerte quedaría para disposiciones de libre voluntad. El testador recuperaría libertad para disponer de bienes a favor de terceros, sin perder la que tiene actualmente para disponer de ellos a favor de quienes actualmente son asignatarios de mejora y legitimarios. La derogación de la cuarta de mejoras supondría un verdadero restablecimiento de la libertad de testar en Chile. Esta medida sería un estímulo para el uso del testamento como instrumento de ordenación sucesoria.

Otro estímulo que se observa, aunque no se discute en este artículo, sería la derogación del impuesto a las herencias y donaciones, o un considerable aumento de los tramos exentos de este impuesto. Estas dos medidas podrían prevenir la transmisión de bienes por actos entre vivos que buscan eludir las restricciones que tiene la disposición de bienes por testamento y el impuesto a las herencias y donaciones. La derogación de la cuarta de mejoras y del impuesto a las herencias y donaciones (o un considerable aumento en los tramos exentos) iría en la línea de devolver a los particulares la libertad de disponer de sus bienes, como ha hecho, por ejemplo, Colombia.

Derogada que sea la mejora, otras dos medidas correctivas que deberían considerarse para aumentar la libertad de testar en Chile son la disminución de la cuantía o calidad de la legítima de los ascendientes; y la disminución de la cuantía y calidad de la actual legítima del cónyuge o conviviente civil sobreviviente. La legítima de los ascendientes podría disminuir en cuantía si se reduce, por ejemplo, a una cuarta parte del acervo. Otra forma de reducir esta legítima es transformarla en una asignación alimentaria, que se lleva solo si el asignatario no tiene bienes o los que tiene son de menor cuantía que lo que le correspondería llevar en la herencia del causante.

La legítima del cónyuge (o conviviente civil) sobreviviente se reduciría en cuantía si, cuando concurre con hijos del causante, el sobreviviente lleva lo mismo que por legítima rigorosa toca a un hijo, nunca más que eso. Esto supone derogar la porción mínima que la ley asegura a este legitimario cuando concurre con hijos del causante. Reconocer al cónyuge (o conviviente civil) sobreviviente la calidad de legitimario debería suponer que sea obligado a imputar a lo que recibe por legítima todas las asignaciones testamentarias que le haga el causante, salvo disposición expresa, como deben hacer los demás legitimarios.

\section{Referencias}

Alessandri Rodríguez, A., Reformas introducidas al Código Civil por la Ley 10.271, Santiago, Ediar Editores, 1955.

Barría Paredes, M., Asignaciones forzosas y libertad de testar, Santiago, Legal Publishing Chile, 2015.

Bello, A., Obras completas. Amunátegui Reyes, M. L. (ed.), Santiago, Imprenta de P. Ramírez G., 1881 (Referencias a volumen y número original.) 
Claro Solar, L., Explicaciones de Derecho Civil chileno y comparado (edición de los 17 tomos en siete volúmenes), Santiago, Editorial Jurídica de Chile, 2013. (Referencias al tomo y número original de la obra.)

Corral Talciani, H., "Los nuevos órdenes de sucesión abintestato", en ID. (ed.), Derecho sucesorio actual y adjudicación de la vivienda familiar: Las reformas de la ley $n .^{\circ} 19.585$ de 1998, Santiago, Ediciones Universidad de los Andes, 2000, 33-48.

Corral Talciani, H., “Derecho sucesorio: ¿eliminar o mejorar la mejora?”, columna de opinión, 2011, disponible en [https://corraltalciani.wordpress.com/2011/ 02/14/derecho-sucesorio-\%C2\%BFeliminar-o-mejorar-la-mejora/] [visitado el 14 de mayo de 2019).

Corral Talciani, H., Curso de Derecho Civil. Parte general, Santiago, Chile, Legal Publishing, 2018.

Calderón Torres, P. "Beneficios tributarios por donaciones”, en Revista de Estudios Tributarios, n. ${ }^{\circ}$ 1, 2010,97-131, disponible en [https://revistaestudiostributarios. uchile.cl/index.php/RET/article/view/41234/42769] [consultado el 14 de mayo de 2019].

Calderón Torres, P. “Aplicación práctica de los beneficios tributarios a las donaciones", en Revista de Estudios Tributarios, n. ${ }^{\circ}$ 4, 2011, 85-121, disponible en [https://revistaestudiostributarios.uchile.cl/index.php/RET/article/download/411 46/42684/] [consultado el 14 de mayo de 2019].

Domínguez Benavente, R. y Domínguez Águila, R., Apéndice a la Segunda edición actualizada de Derecho Sucesorio. Modificación al contenido de la obra, Santiago, Editorial Jurídica de Chile, 1998.

Domínguez Benavente, R. y Domínguez Águila, R., Derecho Sucesorio, 3. a edición, Santiago: Editorial Jurídica de Chile, 2011.

Elorriaga de Bonis, F. Derecho Sucesorio, 3. a edición actualizada, Santiago, Legal Publishing Chile, 2015.

Guzmán Brito, A., Derecho Privado Romano, Santiago, Editorial Jurídica de Chile, 2004.

Martinic Galetovic, M. D., "Las asignaciones forzosas y la libertad de testar en el Derecho chileno", en Revista Jurídica, n. ${ }^{\circ 5,2002,69-75 .}$ 
Peralta Abogados, Guía sobre incentivos tributarios a donaciones, 2018, disponible en [https://irade.cl/wp-content/uploads/2018/11/guia-donaciones-2018.pdf] [visitado el 14 de mayo de 2019].

Rodríguez Grez, P. Instituciones de Derecho Sucesorio, Santiago, Editorial Jurídica de Chile, 2002.

SaAvedra Alvarado, E., “Autonomía de la voluntad y protección de la familia frente a la actual realidad sucesoria: la búsqueda de nuevos equilibrios entre dos principios fundamentales", en Corral Talciani, H. (coord.), Estudios de Derecho Civil, II, Santiago, Editorial LexisNexis, 2007, 113-132.

Saffie Gatica, F., "El impuesto a las herencias como una institución de justicia", Estudios Públicos, n. ${ }^{\circ}$ 126, 2012, 126-161, disponible en [www.cepchile.cl/cep/ site/docs/20160304/20160304095919/rev126_FSaffie.pdf] [consultado el $30 \mathrm{de}$ enero de 2020].

SAmPer Polo, F., Derecho Romano, Santander, Imprenta Guzmán, 1984.

Somarriva Undurraga, M., Evolución del Código Civil chileno, Santiago, Editorial Nascimento, 1955.

Suau Cot, V., La libertad de testar y sus límites: hacia una reforma de las asignaciones forzosas. Facultad de Derecho, Universidad de Chile. Tesis para optar al grado académico de licenciada en Ciencias Jurídicas y Sociales dirigida por la profesora Fabiola Lathrop Gómez, Santiago, 2015, disponible en [http://repositorio.uchile.cl/bitstream/handle/2250/133419/La-libertad-de-testar-y-sus$1 \%$ EDmites-hacia-una-reforma-de-las-asignaciones-forzosas.pdf?sequence $=1$ ] [visitado el 8 de mayo de 2019].

Truffello, P.; Weidenslaufer, $\mathrm{CH}_{\text {., }}$ "Libertad de testar en el derecho comparado. Visión crítica al sistema chileno". Biblioteca del Congreso Nacional. Departamento de Estudios, Extensión y Publicaciones, 5 de octubre de 2016.

VAras Braun, J. A., "Uniones de Hecho y Derecho Sucesorio (Libertad de testar para solteros sin hijos)", en Revista de Derecho (Valdivia), vol. XXIII, n. ${ }^{\circ}$ 2, 2010, 9-22.

Weidenslaufer von Kretschmann, Ch. y Cavada Herrera, J. P., Impuesto a las herencias en Chile, Reino Unido y EE.UU., Valparaíso, Biblioteca del Congreso Nacional, Asesoría Técnica Legislativa, sup: 236066, 2018, 1-11, disponible en [www.bcn.cl/obtienearchivo?id=repositorio/10221/26779/2/Impuesto_herencias_comparado.pdf]. 


\section{Fuentes legales citadas}

Argentina: Código Civil y Comercial de la Nación, artículos 2.433, 2.436.

Chile: Código Civil chileno, artículos 203, 232, 321, 323, 326, 956, 959, 961, 889, 988, 989, 990, 996, 1.167, 1.181, 1.182, 1.183, 1.184, 1.185, 1.186, 1.187, $1.189,1.191,1.194,1.195,1.198,1.203,1.204,1.337$ regla $10 .^{\mathrm{a}}, 1.774$.

Chile: Constitución Política de la República de Chile, artículo 19, número 24.

Chile: Decreto Ley n. ${ }^{\circ} 824$, de 1974 , sobre impuesto a la renta.

Chile: Derecho Ley n. ${ }^{\circ} 825$, de 1974, sobre impuesto a las ventas y servicios (IVA).

Chile: Ley n. 16.271 , de 1965 , sobre impuesto a las herencias y donaciones.

Chile: Ley n. 20.830, de 2015, sobre acuerdo de unión civil, artículo 16 .

Colombia: Código Civil, artículos 1.226, 1.242.

Perú: Código Civil, artículos 822, 823. 